\title{
Uma aprendizagem em deslocamento: docência, artes visuais e pesquisa ${ }^{1}$
}

\author{
Aline Nunes (UDESC)
}

\section{RESUMO}

Neste artigo proponho uma escrita construída a partir dos atravessamentos que acontecem entre a experiência vivida na docência, enquanto professora do curso de Artes Visuais da UDESC, e as ressonâncias da pesquisa doutoral "Sobre mudar de paisagens, sobre mirar com outros olhos: narrativas a partir de deslocamentos territoriais". As relações entre docência, artes visuais e pesquisa são construídas em diálogo com o conceito de desterritorialização (DELEUZE e GUATTARI, 1989; 1997; 1997a), uma vez que estes três eixos são aqui entendidos como territorialidades.

PALAVRAS-CHAVE: Deslocamentos; Desterritorialização; Artes Visuais; Docência; Pesquisa.

\section{Resumen}

En este artículo propongo una escritura construida desde los atravesamientos que se pasan entre la experiencia vivida en la docencia, como maestra en el curso de Artes Visuales de la Universidade do Estado de Santa Catarina- UDESC-BR, y las resonancias de la investigación doctoral "Sobre mudar de paisagens, sobre mirar com outros olhos: narrativas a partir de deslocamentos territoriais". Las relaciones entre docencia, artes visuales y investigación son construidas en diálogo con el concepto de desterritorialización (DELEUZE e GUATTARI, 1989; 1997; 1997a), a la vez que los tres ejes temáticos son entendidos como territorialidades.

Palabras clave:Desplazamientos; Desterritorialización; Artes Visuales; Docencia; Investigación

Defendida no ano de 2015, pelo Programa de Pós-Graduação em Arte e Cultura Visual. A pesquisa foi orientada pela Professora Doutora Alice Fátima Martins, na linha de pesquisa Culturas da Imagem e Processos de Mediação e foi integralmente financiada pela CAPES.

$$
=92=
$$




\section{APOTHEKE}

ESTÚDIO DE

P I N T URA

Pelo menos uma vez na vida, a reflexão sobre nós mesmos nos leva a examinar as circusntâncias do nosso nascimento. Por que teremos nascido nesse canto do mundo em particular? As famílias em que nascemos, os países e as cidades a que a loteria da vida nos destina devemos supostamente amá-los, e no fim das contas de fato os amamos do fundo do coração, mas será que não merecíamos melhor sorte? Às vezes me considero desafortunado por ter nascido numa cidade velha e empobrecida, sepultada sob as cinzas de um império arruinado. Mas uma voz dentro de mim insiste em dizer que, na verdade, essa foi a minha sorte. (PAMUK, 20072)
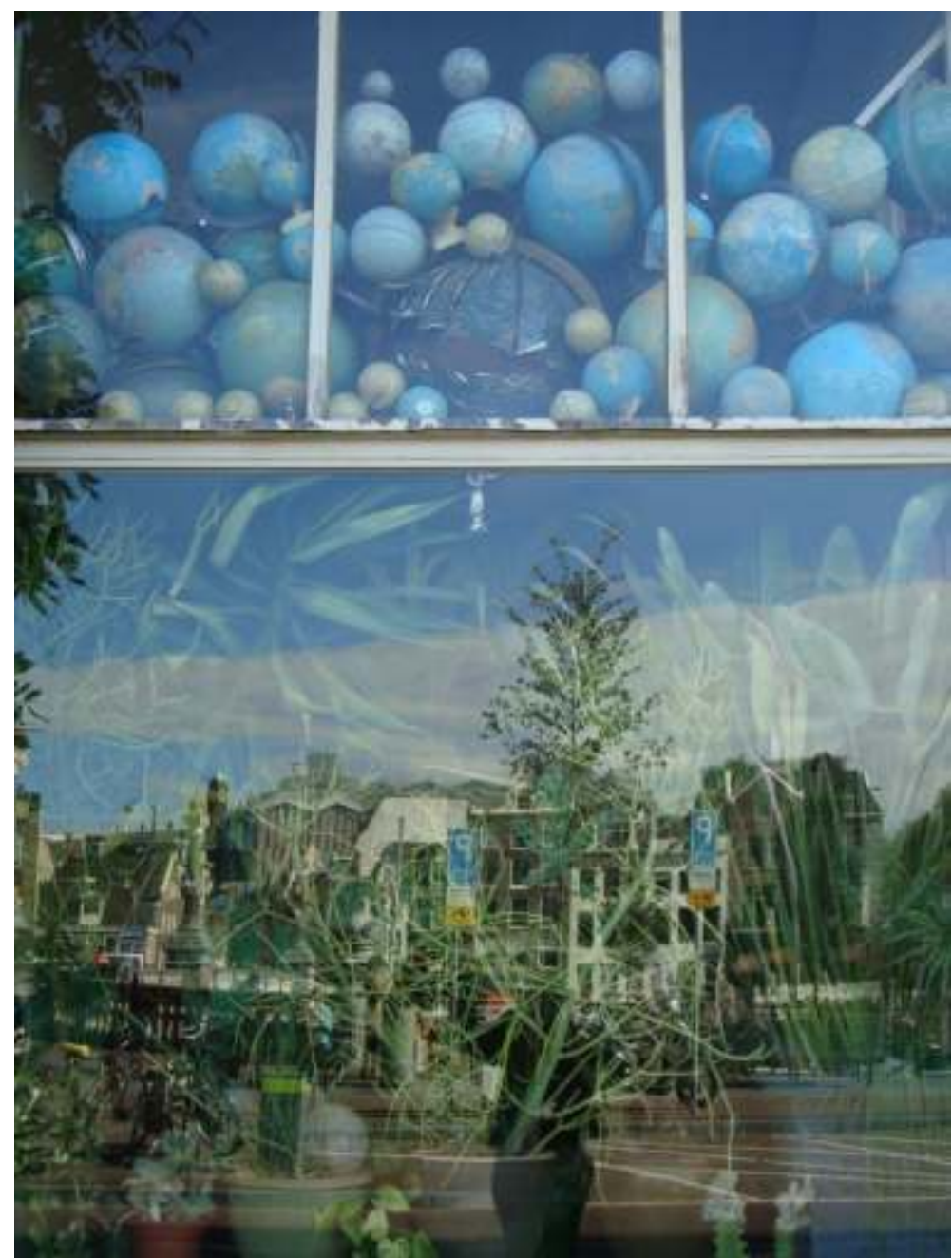

Imagem 1: sem título (2013). Aline Nunes. Fonte: arquivo pessoal.

Fragmento do livro "Istambul", de Orhan Pamuk. Publicado pela editora Cia. Das Letras, em 2007.

$$
=93=
$$

ISSN: 2447-1267 Santa Catarina, v.5, n.1, ano 3, março de 2017. 


\section{Sobre coisas menores}

Procuro abordar o tema "Pesquisa: Ensino e Poéticas Visuais", proposto nesta edição da Revista, problematizando o ato de pesquisar enquanto algo que se faz de modo orgânico, isto é, imbricado aos processos formais - instaurados nos âmbitos acadêmicos - mas que se faz também enquanto fazemos outros planos, enquanto transitamos por outros espaços, nos momentos em que nos descobrimos fazedores de "coisas menores", nas conversas despretensiosas ou, nas horinhas de descuido...3

Me parece ser este o ponto de partida para ensaiar uma conversação. E para tanto, defendo a necessidade de criar um viés distinto, que nos possibilite mirar o âmbito da pesquisa em arte, da pesquisa em educação e das pesquisas em cultura visual na potencialidade de suas interlocuções. Criar caminhos que nos desloquem daquilo que está postulado, que nos é apresentado como campos estanques, por vezes tão cheios de purismos e normativas. Falo sobre profanar os lugares demarcados da docência, da pesquisa, dos campos de saber.

\section{Começar pelo meio}

Como pessoas que vivenciam processos de mudanças territoriais produzem em si deslocamentos para além da mudança de cidade, estado ou país? Que mudanças, que torções de pensamento acontecem em meio a estas experiências, produzindo desterritorializações? Que mudanças são disparadas, e que aprendizagens acontecem?

As perguntas que disparam esta escrita ${ }^{4}$ em parte configuram-se das questões que perpassaram minha tese doutoral. Nesta pesquisa, as narrativas autobiográficas produzidas em torno ao tema do deslocamento territorial foram potências para aprender: sobre o outro, sobre mim, e sobre como nos construímos na medida em que nos deixamos tocar, encharcar, contaminar, produzindo assim mudanças naquilo que temos como territorialidades.

Deleuze e Guattari (1988; 1997; 1997a) em seu conceito de desterritorialização dizem que, para que haja tal ruptura é

${ }^{3}$ Como nos diz Guimarães Rosa.

${ }^{4}$ Partes deste artigo foram citadas em um texto inicial, intitulado: "Uma aprendizagem em deslocamento: territórios e paisagens inventadas", apresentado no Ciclo de Investigações do PPGAV- UDESC, 2016.

$$
=94=
$$

ISSN: 2447-1267 Santa Catarina, v.5, n.1, ano 3, março de 2017. 
necessário que antes haja um território, com fronteiras demarcadas. Ainda, reforçam a ideia de que, havendo desterritorialização haverá, por conseguinte, novos movimentos de reterritorialização, pois que, haverá sempre a necessidade de se criar novos portos e novas terras por onde estabelecer outros vínculos. A reterritorialização compreende um reposicionamento, ainda que provisório: pressupõe novas aprendizagens em outras relações, mas mantendo ainda o elemento desterritorializado (NUNES, 2015).

Quando nos deslocamos entre lugares, saindo de um território para (aos poucos) conquistarmos outro, como vamos narrando a nós mesmos a partir deste ato? Como nos reposicionamos a partir da saída de um lugar já conhecido para outros, sem vínculos e propriedades, nos quais se tem a possibilidade de contar-se de outros modos e de criar novos laços?

Neste processo, os movimentos de desterritorialização e reterritorialização, não tinham a ver com o ato de deixar ou ganhar territórios geográficos, mas sim, produziam abalos, revisões de mundos, afetos, negociações consigo e com o outro, movimentos, estados de território.

No decorrer do exercício de pensar sobre o tema de investigação fui percebendo que as mudanças mais importantes não se tratavam exclusivamente do lugar em si, geográfico, mas daquilo que se é capaz de agenciar a partir dele.

Meu encontro com o conceito de desterritorialização acabou se mostrando potente para pensar, problematizar ou mesmo, para produzir possibilidades de experimentação, que estivessem implicadas e interviessem nos modos com que nos relacionamos e lidamos com os desejos de partida e as mudanças de territorialidades. O conceito, por sua vez, não foi tomado como totalidade de um pensamento. Ele foi empregado para cartografar um processo, utilizado de forma fragmentada, naquilo que me parecia conveniente.

Das derivas produzidas nesta tese doutoral, mais do que registrar vivências e memórias, dando conta de fatos, acontecimentos e da própria sucessão de acontecimentos relacionados às viagens, o intuito foi convidar outros sujeitos a pensarem sobre o que neles era deslocado enquanto se deslocavam. Pensar sobre a própria condição de sentir-se estrangeiro de si, na medida em que se abriam ao risco desta experiência, colocando-se em estado de espreita (DELEUZE e PARNET, 1988) em nome da

$$
=95=
$$


possibilidade de dar vazão ao que é diferente daquilo que já lhes era sabido.

Ou seja: no caso do processo empreendido, importou-me conhecer e também dar visibilidade àquilo que era fabricado, inventado e torcido a partir das mudanças territoriais vividas.

Preciosa (2010) nos fala sobre este sujeito que, confrontado por suas experiências, é capaz de sair de si, ver-se outro, mas que para isso é necessário um esforço para torcer este sujeito ao qual se acostumou a ser. É preciso investimento, é preciso correr o risco.

\section{Movimentos de dispersão}

Primeiro, caminhe até tua primeira planta e lá observe atentamente como escoa a água de torrente a partir deste ponto. A chuva deve ter transportado os grãos para longe. Siga as valas que a água escavou, e assim conhecerá a direção do escoamento. Busque então a planta que, nesta direção, encontra-se o mais afastado da tua. Todas aquelas que crescem entre estas duas são para ti. Mais tarde, quando estas últimas derem por sua vez grãos, tu poderás, seguindo o curso das águas, a partir de cada uma destas plantas, aumentar teu território. (CASTAÑEDA, apud DELEUZE e GUATTARI, 1995, p.21)

Embora minhas perguntas de tese nunca tenham se dirigido de modo explícito ao âmbito da educação ou mesmo da reflexão/proposição em torno à criação poética no campo das Artes Visuais, vejo o quanto este trabalho me levou a pensar e assumir novas perspectivas sobre estes territórios. Mais ainda: vejo o quanto minha tese fornecia ferramentas para que eu pudesse operar nestes campos.

Naquilo que me competia escolha, em minha formação acabei optando pela diversidade, pelos caminhos que me faziam sair dos lugares que me eram habituais. Graduação em Artes Visuais, Mestrado em Educação, Doutorado em Arte e Cultura Visual. Dentro disso tudo, linhas de pesquisa que me faziam querer explorar aquilo que estava mais além, em zonas fronteiriças: cinema, filosofia, antropologia, geografia. Lugares que não eram meus, mas nos quais eu poderia adentrar.

Num retorno às paginas da tese, me encontro com o seguinte fragmento: 
Prefiro, ao menos por ora, 'a liberdade do caminho das infidelidades e traições teóricas, dos deslocamentos institucionais, das derivas existenciais, dos encontros ocasionais e inesperados. Com medo, com riscos.' (LOPES apud NUNES, 2015, p.40)

Minha discussão acerca de deslocamentos territoriais, de alguma forma, me levava a defender uma escolha para além da geografia: fazia-me renovar votos com aquilo que escolhi profissionalmente. Levava-me a ver a professora na qual fui me forjando, justamente nos trânsitos entre diferentes espaços acadêmicos, nas infidelidades teóricas, na abertura para ouvir aquilo que me é partilhado pelo outro que atravessa meu caminho.

Não obstante, dos fios de sentido que a tese me forneceu, pude ver também relações com minhas produções artísticas do passado ${ }^{5}$, ainda, com as novas elaborações de agora. ${ }^{6}$ o olhar para os mapas, a (re) construção de lugares afetivos e a apropriação de imagens com intuito de conformar novos territórios constituem-se como parte fundamental nos processos de experimentação com as linguagens artísticas. Ainda, vejo o quanto as problematizações em torno às relações com as cidades, a cultura e as narrativas que se produzem são materialidades para a elaboração de muitas das experimentações artísticas.

Em maior ou menor intensidade, percebo que falar, pensar, experimentar sobre o tema do deslocamento e do território fez-se enquanto uma presença ativa seja como opção de vida ou como questão a problematizar enquanto pesquisadora, entendendo que estas "porções" não se separam, posto que são coextensivas.

Desde esta concepção, instaura-se também um novo viés para pensar a educação em artes visuais, pautada não somente nas situações regulares e formais de ensino-aprendizagem, vinculadas a escolas, museus e outros espaços educativos. Ante esta posição proposta pela pesquisa, a educação em artes visuais, a experienciação artística, os sentires de quem produz e é atravessado por imagens se dão nos espaços do viver e geram aprendizagens.

${ }^{5}$ Como nos diz Guimarães Rosa. Durante os anos do curso de Bacharelado em Artes Visuais, minha produção poética foi marcada tanto pela não filiação a uma linguagem artística (na qual explorei a linguagem da gravura e do desenho, com colagens e bordados) como também pela busca de uma reflexão sobre o conceito de espaço e de (não) lugar, por meio da criação artística.

${ }^{6} \mathrm{Na}$ produção de fotografias, desenhos, gravuras e outras narrativas visuais que se nutrem das noções de cartografia e paisagem, a partir das territorialidades apropriadas e inventadas no decurso dos últimos seis anos.

$$
=97=
$$




\title{
Sendo catadora
}

As experiências de deslocamento territorial, seguramente, provocaram uma capacidade de observar, de invencionar novas narrativas de vida, marcadas pelos acontecimentos desdobrados de seus trânsitos e seus embates com diferentes meios e contextos culturais.

Deste modo, entendo que a experiência estética está intrinsecamente relacionada aos processos de desterritorialização: marcada pelos fluxos de pensamento, pelos modos de ver transformados na viagem, pelo desejo de apropriação e recriação de paisagens próprias, nas quais outras relações de pertencimento fossem inauguradas.

Esta forma de viver a docência e a experimentação em artes visuais, relacionando-as às ideias de deslocamento e desterritorialização foi possível, em grande medida, pelo contato com as perspectivas teóricas da Cultura Visual e dos estudos pósestruturalistas.

Para Martins:

\begin{abstract}
a cultura visual, entendida não como substantivo, mas como orientação epistemológica, oferece um conjunto interdisciplinar e dialogal de referenciais possíveis as aproximações dos assuntos eleitos para investigação. (2012, p. 228)
\end{abstract}

Mais do que situar o objeto (imagem/artefato visual) e os sentidos que ele produz, importa o contrário deste movimento: os sentidos que produzimos, as conexões que traçamos com espaços, lembranças, histórias vividas em diálogo com outros sujeitos, e que daí resultam matérias onde se possam perceber as relações tramadas, tomando a Cultura Visual como lentes para ver e interatuar nestes processos.

Portanto, assumir como orientação teórico-metodológica a cultura visual possibilitou-me entrecruzar os sentidos que são produzidos por espectadores, autores e demais sistemas a partir das entre-relações entre o que é visto e de como se é visto (HERNÁNDEZ, 2010). Neste caso em particular, tornou-se relevante discutir como as mudanças que derivam dos deslocamentos e demais tipos de transições territoriais estão carregadas de sentidos e embates, expostos nas narrativas (sejam elas orais, visuais, escritas...) que os circundam e constroem.

$$
=98=
$$


No que diz respeito às imagens selecionadas para compor este texto, tratam-se de fragmentos dos percursos realizados: tanto percursos geográficos, como também frutos dos percursos teóricos e metodológicos empreendidos. As visualidades selecionadas para compor este texto, bem como na tese, tem por intuito provocar relações, conexões com e a partir do que é vivido durante o ato de deslocar-se e o pensamento em torno à docência e à arte. De certo forma, pode-se pensar que as imagens que vem sendo catadas, recompiladas e produzidas até aqui atuam como forma de flexibilizar as fronteiras entre os territórios transitados da docência, da arte e da pesquisa, expandindo-os.

\section{Lugares de passagem}

"Un amigo me dijo una vez que el verdadero viaje de descubrimiento no consiste en cambiar de paisaje, sino en mirar con otros ojos".

A partir da deriva, encontram-se superfícies irregulares. Experimentar estas rotas é também uma forma de criá-las, de inventar e "delirar caminhos". Delirar paisagens que só existem nas histórias de cada um, que monta seu quebra-cabeça existencial, a partir das peças catadas durante o percurso.

Nem só de caminhos se cria este quebra-cabeça, muito dele se configura de memórias guardadas: uma cor de céu, um dia de vento norte, o ruído das janelas batendo.

A tese teve como propósito discutir a constituição de paisagens tomando como matérias os escritos, os fragmentos de conversa, as imagens e outros fenômenos visuais (ILLERIS e ARVEDSEN, 2012) que marcaram os deslocamentos vivenciados, observando a partir disso os movimentos de desterritorialização e reterritorialização, contínuos ao longo do percurso investigado.

Das escritas autobiográficas e das imagens relacionadas às suas experiências, partindo de algumas recorrências, deu-se o surgimento de paisagens. As paisagens, contudo, iam além da

${ }^{7}$ Fala da personagem Lucía, no filme "La hija del canibal", em português intitulado como "Aos olhos de uma mulher". 
figuração/representação dos espaços: operavam como ideias e conceitos para dizer desses fluxos de desterritorialização e reterritorialização, percebidos nas narrativas dos sujeitos envolvidos nesse processo.

Estabelecendo um diálogo posterior à tese com aquilo que vivencio neste momento de atuação docente, percebo que estas paisagens são espécies de categorias, possíveis para pensarmos os processos de aprendizagem e formação, seja no âmbito da docência, da pesquisa, ou no âmbito dos processos artísticos.

As paisagens, se entendidas como categorias, nos levam ao conceito de desterritorialização, em seus fluxos de saída/experimentação; reterritorialização/sedimentação e repouso; movimento/ruptura.

Assim, temos como paisagens as seguintes territorialidades:

\section{- Callejeo}

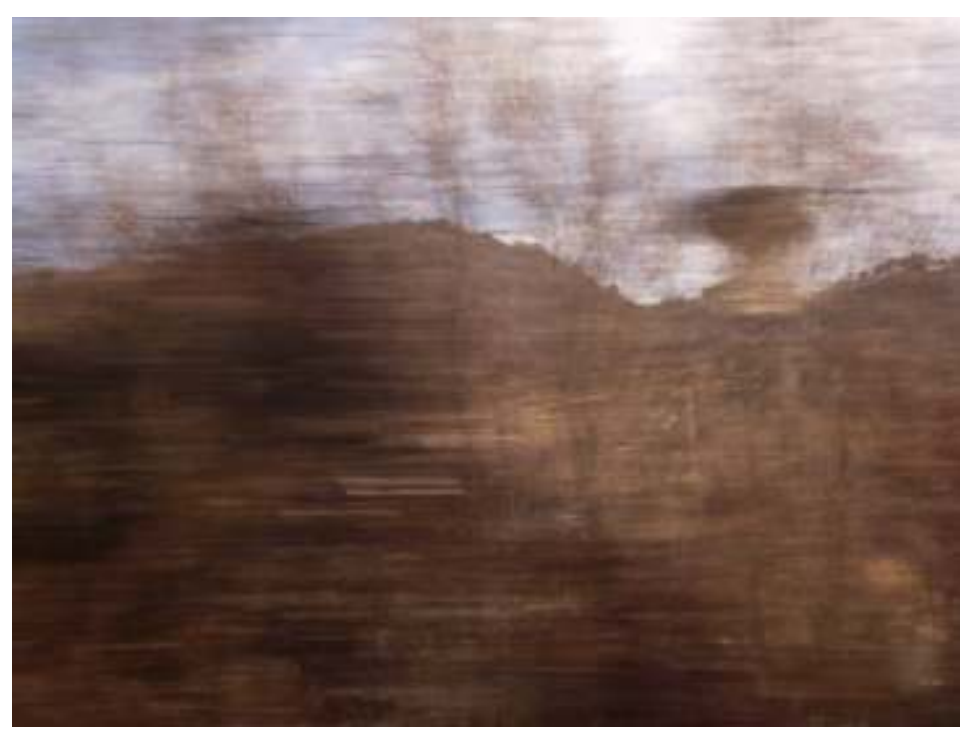

Imagem 1: Voile (2014). Aline Nunes.

Fonte: arquivo pessoal

A ideia de Callejeo enquanto paisagem ajuda a pensarmos na potência existente em se deixar levar, no ato de sair para ver o que pode ser descoberto, capturado durante esse vagar por entre espaços. Por esses movimentos ensaiamos, ainda que timidamente, a possibilidade de fazer diferente daquilo que se mostra como desgastado. A desterritorialização supõe mais do que uma saída de um espaço físico concreto, exige uma desocupação no próprio corpo, daquilo que costumávamos ser. É "a demolição brutal de experiências gastas e formas foscas" (PRECIOSA, 2010, p. 54).

$$
=100=
$$




\section{- Um em casa, outro}

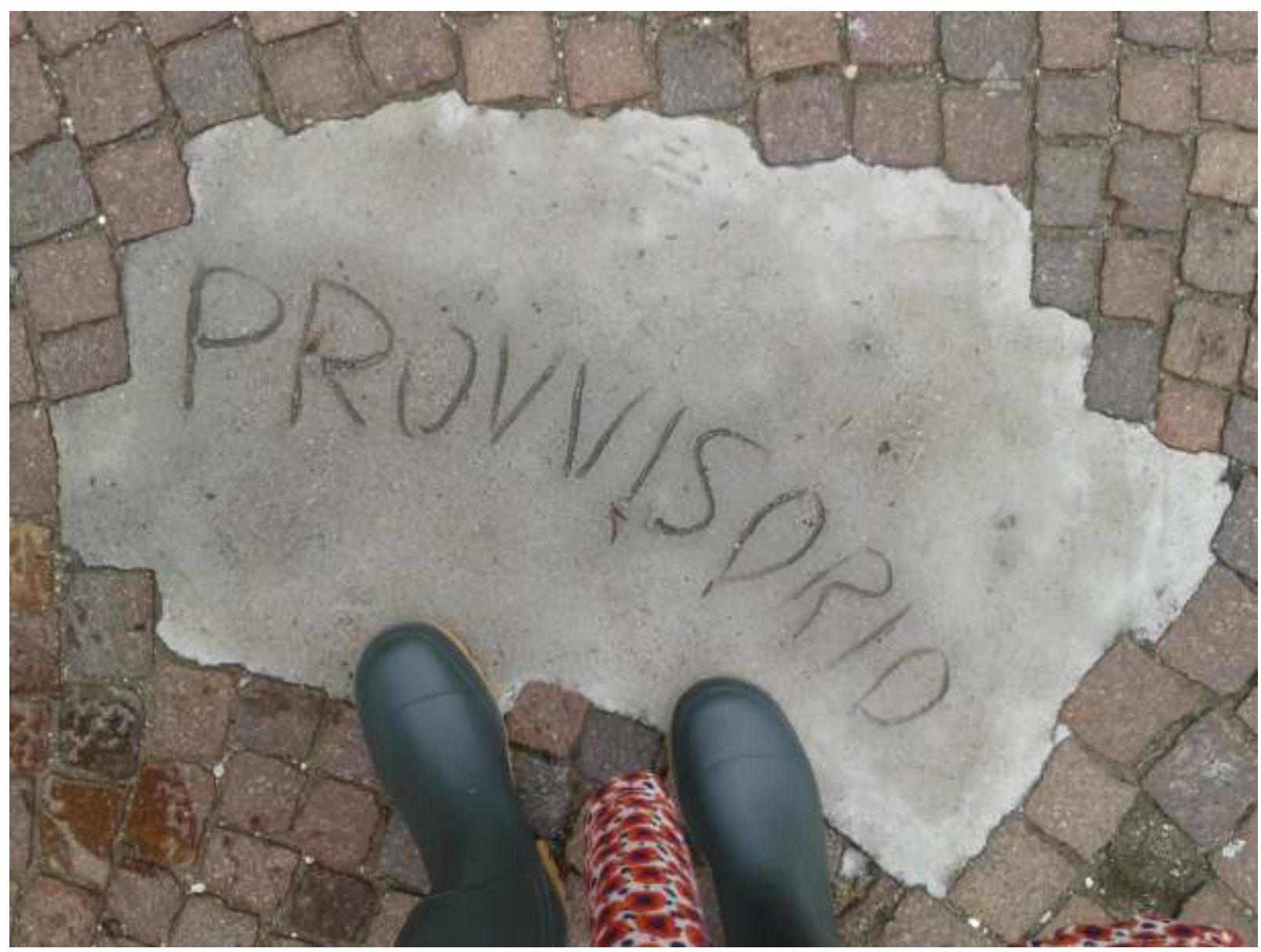

Imagem 2: "Provvisorio" (2013). Aline Nunes. Fonte: arquivo pessoal

Nesta paisagem a casa pode ser pensada enquanto agenciamento (DELEUZE e GUATTARI, 1997), isto é, possibilidade de combinar elementos heterogêneos que, ao serem mesclados, tornar-se-ão distintos daquilo que foram inicialmente, elevando sua potência. Espaço aberto às combinações daquilo que nos importa, daquilo que nos toca e que merece ser guardado, trazido conosco para ser bricolado junto a sentimentos, histórias e imagens que, emaranhados, criam um lugar singular, um lugar de pertencimento.

Os indivíduos nômades não se distinguem dos sedentários pelo desapreço a uma porção territorializada, a que possam chamar de casa. Distinguem-se sim, pela abertura em ver sua casa transformada de tempos em tempos, cambiada, dilacerada por suas próprias conviç̧ões de que mesmo a casa, que congrega uma ideia de fixidez, deve ser efêmera, deve contemplar a possibilidade de virar ruína. A casa talvez mais do que um lugar concreto e endereçado, seja um conceito flutuante criado para dar conta da necessidade de algo que nos faça sentir abrigados, confortados e seguros, e isto tudo é também variável a depender de como e de quem desenha para si esse território.

$$
=101=
$$




\section{- Quem de dentro de si não sai}

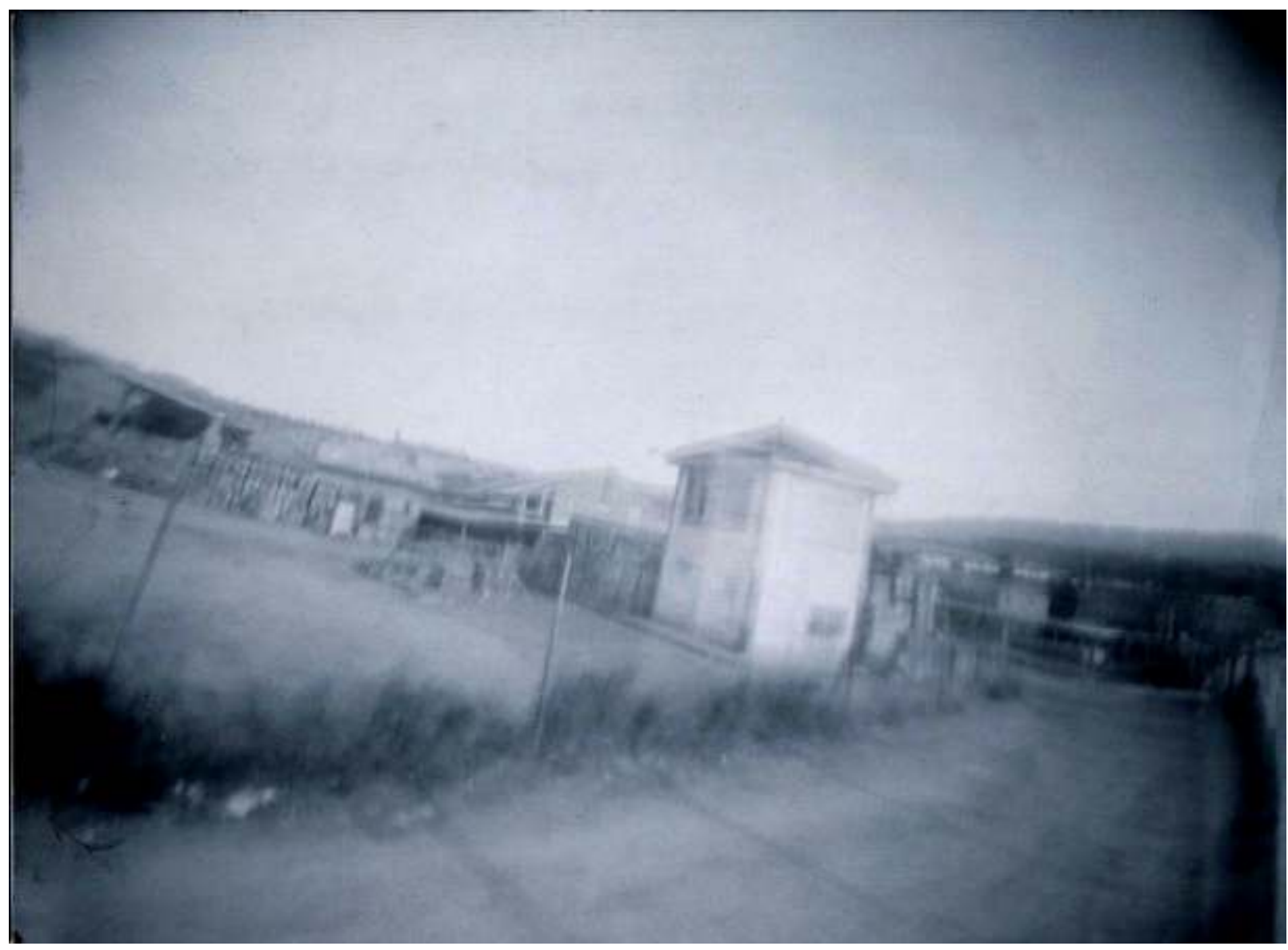

Imagem 3: Bòvila (1982). Olga Pérez García. Fonte:

https://www.facebook.com/photo.php?fbid=10204076599657888\&set=a.3511367105500.172517.13115 66949\&type $=1 \&$ theater

Se, para Deleuze só se pensa porque se é forçado, porque existe algo que, estando fora do pensamento o força a fazer novas conexões, o faz vibrar, rompendo com estratificações e com aquilo que estava cristalizado, esta paisagem é também feita a partir de um esforço, de uma violência no sentido de forçar-nos a pensar, ser e fazer diferentemente daquilo que nos acostumamos. Nem que seja para seguir fazendo como antes.

o que importa é colocar-se em estado de questionamento, permitir-se a dúvida para sair de si, mesmo se optarmos por voltar, pois o retorno nunca será para o mesmo. O sujeito nômade, no decurso de sua marcha, percebe que "lo que es importante es el devenir, el proceso de transformarse en algo diferente, y no necesariamente llegar a serlo" (HORNIKE, 2008, p.66). Por tanto, esta é uma paisagem diretamente relacionada ao conceito de devir; um estado que não se conclui, que está sempre ativo.

$$
=102=
$$




\section{Próxima parada}

o que conta em um caminho, o que conta em uma linha é sempre o meio e não o início nem o fim. Sempre se está no meio do caminho, no meio de alguma coisa. (DELEUZE e PARNET, 1998, p. 39)

Ao lançar esta possibilidade de pensar os sentidos e referências que foram produzidos no decorrer do tempo de pesquisa enquanto paisagens, parto do pressuposto de que estas (assim como os sujeitos implicados nesta narrativa) estão constantemente se transformando. Atuamos e agimos em seus espaços, desmanchamos algumas formas e alguns mundos, e recriamos outros conceitos e perspectivas para experimentá-las.

Vivenciamos processos contínuos de desterritorialização e reterritorialização a partir de experiências ínfimas, menores. Assim, ao longo da tese, defendi que as paisagens se modificam, conforme mudamos nossos pontos de vista, nossos modos de ver e relacionarmo-nos com o que se passa em nossas vidas, sempre de modo engendrado às transformações sociais e à cultura. Nestes processos de transformação, a experiência nos permite aprender, nos condiciona a fazer diferentemente daquilo que já fora feito.

Neste sentido, profissionalmente, tenho atuado de modo a colocar estas paisagens inventadas na tese para funcionar em meu dia-a-dia: no trânsito e, sobretudo nas relações que procuro estabelecer entre as diferentes disciplinas que ministro. ${ }^{8}$ Ao planejar as aulas, entrecruzo olhares sobre educação e experiência artística nas proposições que lanço aos meus alunos, para que entendam que tanto a docência, como a produção e pesquisa em artes podem se retroalimentar. Para isso, é necessário este espirito catador, forjador de coisas, e aberto ao desafio de ensaiar novos diálogos.

Por isso, conceitualmente a desterritorialização e a ideia de deslocamento territorial servem como noções que orientam um modo de viver a docência, de fazer pesquisa (a partir de metodologias mais flexíveis, que fomentem o uso de procedimentos artísticos nos processos de investigar)e de produzir poeticamente.

\footnotetext{
${ }^{8}$ No ano de 2016, por exemplo, ministrei disciplinas como "Introdução à Linguagem Gráfica", "Artes Midiáticas", "Estágio Curricular Supervisionado" e "Desenho Infantil", para turmas iniciantes e mais avançadas dos cursos de Bacharelado e Licenciatura.
} 
A docência que se faz em deslocamento, desterritorializada, atua como lugar de experiência, de reflexão, de criação. Fabricação contínua de territorialidades, de universos nos quais imprimimos nosso estilo, investimos nossos desejos e fabricamos visualidades. Tudo isso carregado de histórias que configuram novas conexões, agenciamentos e, assim, produzem aprendizagens.

Os resultados desses movimentos são ainda muito iniciais, e em razão disso é importante não parar agora, é preciso seguir em movimento, para que outros terrenos sejam revolvidos e outras narrativas possam ser inventadas, sobre paisagens que ainda são devir.

Neste sentido, percebo o quanto a pesquisa segue reverberando, convidando-me a pensar sobre os modos com que atuo enquanto docente de artes em nível de graduação, colocando-me a interrogar sobre aquilo que é, ou deve ser desterritorializado em minha prática e com os grupos discentes com os quais venho atuando.

As paisagens inventadas, citadas anteriormente, servem também como categorias passíveis de dialogar com os processos de aprender, conhecer e problematizar a docência em artes e seu campo de experimentação poética.

Finalmente, posso dizer que os deslocamentos territoriais (e novamente reitero que não se restringem ao âmbito geográfico) são brechas e possíveis que me levam a produzir uma nova narrativa para a pesquisa em artes e a educação das artes visuais. 


\section{APOTHEKE}

EST ÚD I O DE

P I N T URA

\section{Referências}

DELEUZE, Gilles; GUATTARI, Félix. Mil platôs: capitalismo e esquizofrenia. Vol. 4. Rio de Janeiro: Ed. 34, 1997.

DELEUZE, Gilles; GUATTARI, Félix. Mil Platôs: capitalismo e esquizofrenia. Vol. 5. Rio de Janeiro: Ed. 34, 1997a.

DELEUZE, Gilles; PARNET, Claire. O abecedário de Gilles Deleuze: transcrição integral do vídeo, para fins exclusivamente didáticos. Éditions Montparnasse: Paris, 1988 .

HERNÁNDEZ, Fernando. Para a Erina ninguém diz nada...e nós não podemos fazer o que queremos. A educação da cultura visual na educação infantil. In: MARTINS, Raimundo e TOURINHO, Irene. (orgs.) Cultura Visual e infância: quando as imagens invadem a escola... Santa Maria: Editora da UFSM, 2010.pp. 71-85.

HORNIKE, Dafna. Los sujetos nómades en Clarice Lispector y Mayra Santos-Febres. Tese de doutorado. Universidade de Alberta, 2008.

ILLERIS, Helene; AVERDSEN, Karsten. Fenômenos e eventos visuais: algumas reflexões sobre currículo e pedagogia da cultura visual. In: MARTINS, Raimundo e TOURINHO, Irene. (orgs.) Culturas das imagens: desafios para a arte e para a educação. Santa Maria: Editora da UFSM, 2012.pp. 283- 309.

LA HIJA DEL CANÍBAL. Antônio Serrano. 2003. (México)

MARTINS, Alice Fátima. Arena aberta de combates, também alcunhada de Cultura Visual: anotações para uma Aula de Metodologia de Pesquisa. In: MARTINS, Raimundo e TOURINHO, Irene. (orgs.) Culturas das imagens: desafios para a arte e para a educação. Santa Maria: Editora da UFSM, 2012.pp. 211-233.

NUNES, Aline. Sobre mudar de paisagens, sobre mirar com outros olhos: narrativas a partir de deslocamentos territoriais. Tese de Doutorado. Universidade Federal de Goiás, 2015.

PRECIOSA, Rosane. Rumores discretos da subjetividade: sujeito e escritura em processo. Porto Alegre: Sulina: Editora da UFRGS, 2010.

ROLNIK, Suely. Uma insólita viagem à subjetividade - fronteiras com a ética e a c u l t u r a. $\quad 1997$. D i s p o n i v e l e m : http://www.pucsp.br/nucleodesubjetividade/Textos/SUELY/viagemsubjetic.pdf Acesso em 12 de junho de 2012.

\section{Aline Nunes da Rosa}

Doutora em Arte e Cultura Visual pelo Programa de Pós Graduação em Arte e Cultura Visual (PPGACV), da Faculdade de Artes Visuais (FAV), da Universidade Federal de Goiás. Bolsista PDSE-CAPES (Programa Institucional de Bolsas de Doutorado Sanduíche no Exterior), com estágio no programa de Doctorado en Artes y Educación, da Universidad de Barcelona (2013-2014). Bolsista CAPES 2011/2015. Mestre em Educação pelo Programa de Pós Graduação em Educação (PPGE), linha de pesquisa Educação e Artes, da UFSM. Bolsista CAPES 2008/2010. Bacharel e Licenciada em Artes Visuais pela Universidade Federal de Santa Maria. Atualmente é professora colaboradora do Departamento de Artes Visuais da Universidade do Estado de Santa Catarina- UDESC. 